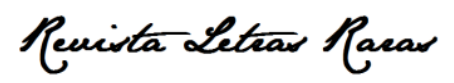

ISSN: 23172347 - Vol. 2 N. 2 - 2013

\title{
"Conceição": a personagem feminina sob os olhares de Machado de Assis e Moacyr Scliar
}

\author{
Ana Beatriz Mayara da Silva Araújo* \\ Maria Bernardete da Nóbrega** \\ Maysa Morais da Silva Vieira**
}

\begin{abstract}
RESUMO:
O presente trabalho consiste na análise dos contos: Missa do Galo, do escritor Machado de Assis, publicado em 1889 na coletânea Páginas recolhidas, e do conto Missa do Galo: Um outro enfoque, do escritor Moacyr Scliar, publicado em 2003. Nosso estudo está voltado para narração original machadiana daquela noite de Natal e para releitura feita por Moacyr Scliar sobre o comportamento da personagem Conceição durante sua conversa com o jovem Nogueira, adentrando não só nos aspectos literários, como também nos aspectos sociais e históricos. Sem deixar de analisar as características psicológicas de Conceição, que podem levar ao leitor obter diferentes interpretações sobre esta personagem. Para isso, fazemos uma análise acerca da evolução do papel feminino na sociedade patriarcal do século XIX, o que facilita a compreensão do conto machadiano; e, na sociedade contemporânea, que através do conto de Scliar, o leitor pode imaginar como seria aquela noite se Conceição já tivesse vivenciado a evolução do papel feminino em nossa sociedade.
\end{abstract}

Palavras-chave: Contos. Missa do Galo. Machado de Assis. Moacyr Scliar. Conceição.

\section{ABSTRACT:}

The present work is the analysis of the tales " Missa do Galo" the writer Machado de Assis, published in 1889 in book Páginas Recolhidas, and of the short story " Missa do Galo: Um outro enfoque" , of the writer Moacyr Scliar, published in 2003. Our study is focused on the original story that Machado's Christmas Eve and re-reading done by Moacyr Scliar on the behavior of the character Conceição during his conversation with the young Nogueira, entering not only the literary aspects, but also in the social and historical aspects. While analyzing the psychological characteristics of Conceição, which may lead the reader to get different interpretations of this character. For this we make an analysis on the evolution of women's role in the patriarchal society of the fourteenth century, which facilitates the understanding of Machado's tale, and in contemporary society, through the tale of Scliar the reader can imagine how that night would be already Conceição had experienced the evolution of women's role in our society.

Keywords: Tales. Missa do Galo. Machado de Assis. Moacyr Scliar. Conceição.

\footnotetext{
* Graduanda em Letras na Universidade Federal da Paraíba. E-mail: beatrizaraujojp@ hotmail.com.

** Orientadora e Professora-Doutora em Letras na Universidade Federal da Paraíba. E-mail: bernanobre2009@hotmail.com.

*** Graduanda em Letras na Universidade Federal da Paraíba. E-mail: maysa.morais@ yahoo.com.br.
} 


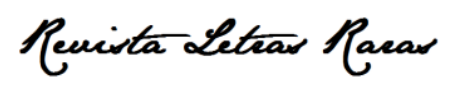

ISSN: 23172347 - Vol. 2 Nº. 2 - 2013

\section{Introdução}

Muitos estudos literários estão voltados para a análise de obras e textos, como também de seus personagens. Alguns personagens são emblemáticos e entre os estudiosos causam certa polêmica e/ou várias interpretações. O escritor Machado de Assis é responsável por criar personagens que ao longo da história vem sendo tema de diversos estudos e pesquisas, já que a literatura machadiana possibilita ao leitor ter as suas próprias convicções sobre o texto. Para compreendermos tais personagens é necessário adentrarmos em seu contexto social, em seu tempo histórico e nos costumes e valores de determinado tempo.

Dentre as diversas temáticas que a obra machadiana nos poderia inspirar a estudar, o presente trabalho vem a observar apresentação da figura feminina no conto Missa do Galo, do escritor Machado de Assis, bem como na releitura contemporânea do escritor Moacyr Scliar. A figura feminina é mostrada a partir de duas visões opostas, estas que estão atreladas ao tempo e ao momento histórico em que estão inseridas. A mulher em Machado de Assis mostra-se mais passiva e submissa, característica das mulheres do século XIX. No entanto, a figura feminina em Moacyr Scliar manifesta-se como um ser liberto das convenções sociais que estão presentes na obra machadiana e surpreende os leitores com o seu comportamento, por assim dizer, mais ousado.

Assim, o presente estudo vem demonstrar as semelhanças e diferenças ideológicas entre os dois contos no que concerne à representação da figura feminina, lembrando-se de que esta personagem é representante de um tempo social a sua posição frente à posição ocupada pelo homem em uma sociedade machista e patriarcal.

\section{Apresentação dos autores}

\subsection{Joaquim Maria machado de Assis}

Joaquim Maria Machado de Assis nasceu no Rio de Janeiro, em 21 de junho de 1839, onde morreu aos 29 dias de setembro de 1908 e é um escritor brasileiro, amplamente, considerado como o maior nome da literatura nacional. Escreveu praticamente todos os gêneros literários, sendo poeta, romancista, cronista, dramaturgo, contista, folhetinista, jornalista e crítico literário. Testemunhou a mudança política no 


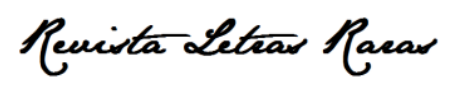

ISSN: 23172347 - Vol. $2 \mathrm{~N}^{\circ} .2$ - 2013

país, quando a República substituiu o Império e foi um grande comentador e relator dos eventos político-sociais de sua época.

Nascido no Morro do Livramento, no Rio de Janeiro, de uma família pobre, estudou em escolas públicas e nunca frequentou universidade. Os seus biógrafos notam que, interessado pela boemia e pela corte, Machado lutou para subir socialmente abastecendo-se de superioridade intelectual. Para isso, assumiu diversos cargos públicos, passando pelo Ministério da Agricultura, do Comércio e das Obras Públicas, conseguindo precoce notoriedade em jornais onde publicava suas primeiras poesias e crônicas. Em sua maturidade, reunido a colegas próximos, fundou e foi o primeiro presidente unânime da Academia Brasileira de Letras.

Suas principais obras são: Ressurreição (1872), A Mão e a Luva (1874), Helena (1876), Iaiá Garcia (1878), Memórias Póstumas de Brás Cubas (1881), Quincas Borba (1891), Dom Casmurro (1899), Esaú e Jacó (1904) e Memorial de Aires (1908), pertencentes ao Realismo brasileiro.

\subsection{Moacyr Scliar}

Moacyr Jaime Scliar nasceu em Porto Alegre, no dia 23 de março de 1937, onde morreu no dia 27 de fevereiro de 2011. Formado em medicina, trabalhou como médico especialista em saúde pública e professor universitário. Sua prolífica obra consiste de contos, romances, ensaios e literatura infanto-juvenil. Também ficou conhecido por suas crônicas nos principais jornais do país.

Seu acervo bibliográfico é vasto e composto por coletânea de contos, crônicas, romances, ficção infanto-juvenil e ensaios.

\section{A personagem Conceição em Machado de Assis}

Em suas obras, Machado de Assis construiu personagens enigmáticas, figuras femininas que deixam no leitor um sentimento de desconfiança e suspense quanto a seus comportamentos e caráter. A mulher é colocada em suas obras como um ser que ora

mostra-se como inocente e virtuoso, ora como traidor e dissimulado. Em suma, a mulher é colocada como um ser incapaz de ter qualquer valorização; é considerada apenas como uma figura de "enfeite" da casa, alguém dedicada apenas ao controle das 


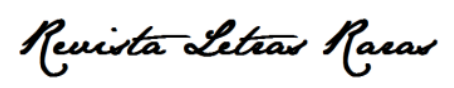

ISSN: 23172347 - Vol. 2 Nº. 2 - 2013

tarefas domésticas, alguém que não se ocupa de nenhuma posição ativa fora do lar e que não tem nenhuma preocupação em obter meios que poderiam inseri-la no convívio social, dada as condições sociais que impunha para elas valores diferentes dos dias atuais. Nas suas obras, Machado optou por mulheres que imprimissem a sociedade machista e patriarcal e que retratassem os antigos padrões da passividade feminina. As mulheres representam as tradições da sociedade brasileira anterior a Machado de Assis: uma sociedade que não dava oportunidades à mulher de ocupar o mesmo espaço destinado aos homens, mas que guardava para elas todas as referências ao "bom comportamento".

Em Missa do Galo, a personagem de D. Conceição é vista pela vizinhança como a representação de uma santa “... Boa Conceição! Chamavam-lhe "a santa”, e fazia jus ao título, tão facilmente suportava os esquecimentos do marido. Em verdade, era um temperamento, sem extremos, nem grandes lágrimas, nem grandes risos" (ASSIS, 2002, p. 2)". D. Conceição é uma mulher que suporta a indiferença do marido e até mesmo sabendo da traição dele, mantinha-se passiva.

\footnotetext{
... Vestia-se; saía e só tornava na manhã seguinte. Mais tarde eu soube que o teatro era um eufemismo em ação. Menezes trazia amores com uma senhora, separada do marido, e dormia fora de casa uma vez por semana. Conceição padecera, a princípio, com a existência da comborça: mas, afinal, resignara-se, acostumara-se, e acabou achando que era muito direito. (ASSIS, 2002, p. 1).
}

Observando-se a Conceição de atitudes passivas, vemos uma mulher religiosa, que repudiava os dois quadros tidos para ela como vulgares que foram fixados na parede pelo marido e que preferia "duas imagens de santa”. Era o exemplo da mulher casada: honesta, séria e submissa. De atitudes moderadas e personalidade passiva, Conceição é a típica mulher ociosa que gosta de leituras românticas a fim de ocupar seu tempo, mas que cultiva em seu íntimo, desejos libidinosos: “... De vez em quando passava a língua pelos beiços, para umedecê-los ...” (ASSIS, 2002, p. 1).

A partir desse momento da narrativa, a personagem Conceição assume outra postura, não mais angelical, inocente, mas sim alguém que possui vontades. Dessa forma, ela é uma representante do caráter dissimulado da mulher machadiana: aquela que mantém às vistas da sociedade um comportamento digno, exemplo da moral e bons costumes, mas que cultiva em seu íntimo desejos libertinos, nunca totalmente revelados, 


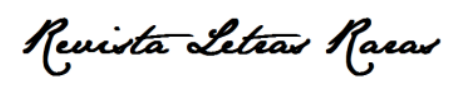

ISSN: 23172347 - Vol. 2 Nº. 2 - 2013

pois os mantêm enrustidos. Conceição é uma mulher de trinta anos, jovem e disposta a manter um relacionamento estável com seu marido Menezes. Mas isto não acontece devido ao descaso com que este que, além de tratá-la de acordo com o respeito que a sociedade impunha ao relacionamento marido/mulher, mantém um relacionamento extraconjugal para o qual dispensa muito de seu tempo: "Menezes trazia amores com uma senhora, separada do marido, e dormia fora de casa uma vez por semana" (ASSIS, 2002, p. 1).

Assim que Conceição tem a oportunidade de estar a sós com o jovem rapaz de nome Nogueira, de dezessete anos, que veio da cidade de Mangaratiba e se hospedara na casa do escrivão Menezes, seu marido, no Rio de Janeiro para os estudos preparatórios, ela aproveita essa oportunidade para um jogo de insinuações e seduções em busca da sua conquista. A se ver a sós com um jovem rapaz, menos experiente que ela, Conceição se livra das convenções sociais e inicia uma progressiva transformação. Ela sai da passividade, pois "Tudo nela era atenuado e passivo" (ASSIS, 2002, p. 2), para alguém de atividade, pois em um dos momentos em que o estudante faz menção de se levantar ela o impede, retendo-o: “- D. Conceição, creio que vão sendo horas, e eu ... / - Não, não, ainda é cedo. Vi agora mesmo o relógio, são onze e meia. Tem tempo." (ASSIS, 2002, p. 2). D. Conceição expõe a sua sensualidade e se apresenta como mulher audaz e uma aproximação física entre ela e o jovem Nogueira se faz progressivamente: “... ela foi sentar-se na cadeira que ficava defronte de mim, perto do canapé"; "E não saía daquela posição que me enchia de gosto, tão perto ficavam as nossas caras"; "Deu volta à mesa e veio sentar-se de meu lado". (ASSIS, 2002, p. 2-3). Todas as atitudes de D. Conceição parecem intencionais. São tentativas para envolver e seduzir Nogueira. A aproximação dos corpos, as partes do corpo que se mostram sutilmente, o contato físico: tudo adquire uma tonalidade sensual.

O possível caráter dissimulado de D. Conceição é ainda mais visível no final do conto quando o narrador menciona, sugestivamente, o possível caso vivido por ela, pois com a morte de seu cônjuge, D. Conceição se casou alguns meses depois com o escrevente juramentado de seu marido.

... Pelo Ano-Bom fui para Mangaratiba. Quando tornei ao Rio de Janeiro, em março, o escrivão tinha morrido de apoplexia. Conceição morava no Engenho Novo, mas nem a visitei nem a encontrei. Ouvi 


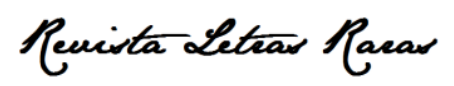

ISSN: 23172347 - Vol. 2 Nº. 2 - 2013

mais tarde que casara com o escrevente juramentado do marido. (ASSIS, 2002, p. 7).

Mas como é característico da obra de Machado de Assis, neste conto tudo é sugerido, nada é provado. Com uma narrativa ambígua, a questão da personalidade sugestiva de D. Conceição permanece aberta e o leitor, assim como o narrador compartilham das mesmas dúvidas e suspeitas em torno de D. Conceição, indecisos em meio à dificuldade de uma interpretação precisa.

\section{A personagem Conceição em Moacyr Scliar}

Missa do Galo na visão de Moacyr Scliar traz outro enfoque do conto Machadiano. Nele, o narrador-personagem é a própria Conceição, o que permite ao leitor perceber os sentimentos de conceição durante a conversação com Nogueira.

Nunca pude entender a conversação que tive com um rapaz, há muitos anos, contava eu trinta, ele dezessete. Era noite de Natal, véspera da tradicional missa do galo, missa essa a qual o rapaz iria com um vizinho. Por causa disso, preferiu não dormir; e, porque preferiu não dormir, algo aconteceu, algo que mudou minha vida. (SCLIAR, 2008, p. 48).

Conceição vai narrando a história contando como era sua família, seus costumes e hábitos.

Nossa família era pequena, o escrivão, eu, Conceição, minha mãe e duas escravas. Mantínhamos velhos costumes."; "Meneses tinha uma amante, uma senhora separada do marido; dormia com ela uma vez por semana. De início aquilo me revoltara; mas, afinal, resignada, eu me acostumara com a traição achando até que era muito direito: Meneses não era o único a ter casos extraconjugais. (SCLIAR, 2008, p. 48).

Inicia-se a conversação com Nogueira, aqui a personagem Conceição nos mostra o ímpeto dos seus pensamentos.

Deitada em meu quarto, eu não podia conciliar o sono. Não era só por causa da ausência de Meneses. Era outra coisa, uma estranha inquietude que não me deixava dormir... E aí, num impulso, levanteime. Vesti um roupão, calcei as chinelas de alcova e ("Mas o que estás fazendo, mulher? Estás louca?") Dirigi-me para a sala em que estava o 


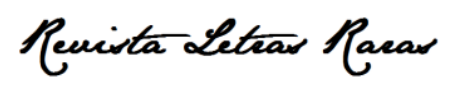

ISSN: 23172347 - Vol. $2 \mathrm{~N}^{\circ} .2$ - 2013

rapaz, e depois de uma hesitação ("Seja o que Deus quiser") entrei. Como esperava, ele ainda estava ali. (SCLIAR, 2008, p. 49).

Scliar, diferentemente de Machado, mostra o pensamento da Conceição para que o leitor tire as suas conclusões acerca da conduta da personagem.

Em seguida, endireitei a cabeça, cruzei os dedos e sobre eles pousei o queixo, os cotovelos nos braços da cadeira, sempre a mira-lo. Era uma pose sedutora? Para mim era, mas por que estava fazendo aquela pose sedutora? O que esperava? A dúvida me angustiava, mas, ao mesmo tempo, me excitava. Eu nunca tinha vivido uma situação assim. Ele, aparentemente, não percebia o que se passava. (SCLIAR, 2008, p. 48).

E ainda:

Pouco a pouco, tinha-me inclinado; fincara os cotovelos no mármore da mesa e metera o rosto entre as mãos espalmadas. Não estando abotoadas, as mangas caíam naturalmente, e ele certamente podia verme os braços, metade deles ao menos... "Claramente estava perturbado talvez pela visão de veias muito azuis... (SCLIAR, 2008, p. $51)$.

Nesses trechos da narrativa também podemos observar uma Conceição sensual e provocante e que se mostra decidida a tentar algo mais do que uma conversação com o jovem Nogueira: "Por instantes, eu cerrava os olhos, o que, disso eu estava segura, dava-me uma aparência de mulher fatal. Mas infelizmente ele pensava que eu estava com sono. Mas certamente estava fascinado por mim." (SCLIAR, 2008, p. 52); “Já agora eu não trocava de lugar, como a princípio, quase não saia da mesma posição. Porque de mim desaparecera, sem que eu soubesse como, nem por que, qualquer impulso erótico.” (SCLIAR, 2008, p. 53). No entanto, o autor quebra as expectativas do leitor quanto a uma possível relação mais íntima entre os dois personagens e, até mesmo, um desencantamento de Conceição por aquela conversa.

No desfecho do Conto Scliar nos surpreende com um final incrível, a resignada Conceição torna-se vilã e vinga-se do seu marido, o escrivão Meneses de uma forma espetacular.

Meneses perguntou-me, casualmente, como tinha sido a noite que precedera a missa do galo. A indagação teve sobre mim um efeito extraordinário. De repente, eu me dava conta de que o momento da vingança tinha chegado. E seria uma vingança insólita, original. Subitamente inspirada, contei-lhe uma história quem nem Dumas nem 


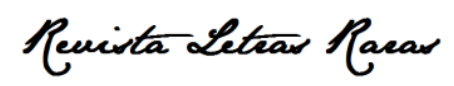

ISSN: 23172347 - Vol. $2 \mathrm{~N}^{\circ} .2$ - 2013

Macedo teriam inventado. Uma história de tórrida paixão entre uma mulher de trinta anos e um rapaz de dezessete, um episódio de sedução capaz de causar inveja a qualquer Cleópatra, a qualquer cortesã. Cenas de sexo explicito, com os detalhes mais picantes que se pode imaginar."; "Meneses ouvia-me entre atônito e furioso. De repente levantou-se; ia dizer qualquer coisa, ou talvez ia bater-me. Não o conseguia. Com um grito espantoso caiu no chão: apoplexia. Em poucos dias estava morto". (SCLIAR, 2008, p. 54).

A Conceição que era "Santa", resignada, que aguentava tudo passivamente, revolta-se e surpreende o marido, narrando uma história que estava em seus pensamentos, desejos, implícitos naquela noite, a noite da Missa do Galo. Portanto, Scliar nos dá um desfecho para o conto, mas nos deixa julgar, condenar ou não, as ações da Conceição.

\section{O papel da mulher no contexto social das duas obras}

As obras de Machado de Assis introduziram o Realismo no Brasil e, em pleno século XIX, mostrou o cotidiano da sociedade brasileira que começava a sofrer uma série de transformações que culminaram no advento do capitalismo e na consequente urbanização que passou a permitir novas formas de convivência social. A ascensão dessa nova classe social, a burguesia, trouxe para a sociedade uma nova mentalidade, uma maneira diferente de organização das vivências familiares e domésticas. O homem agora está diante de uma mulher que se entrega facilmente à sensibilidade e as novas formas de pensar o amor.

Outro aspecto relevante dos romances realistas de Machado de Assis é que nestes há sempre uma voz narrativa, um personagem central, sempre masculino. Como o narrador é esse personagem central toda a narrativa está condicionada a sua própria visão dos acontecimentos. Além disso, o personagem faz a sua narrativa em um tempo muito posterior ao dos acontecimentos narrados. Já velho, rancoroso e magoado com os acontecimentos da vida amorosa fracassada é compreensível o fato de estes terem uma visão negativa da figura feminina. É o que acontece no conto Missa do Galo que, em Machado de Assis, é narrado pelo personagem Nogueira. Em contraponto, na versão de Moacyr Scliar os fatos são narrados pela própria Conceição, assim, percebemos alguns detalhes dos sentimentos e das verdadeiras intenções da personagem naquela noite de 


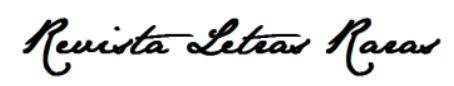

ISSN: 23172347 - Vol. 2 Nº. 2 - 2013

Natal. Diante disso, podemos dizer que a narrativa machadiana apresenta o ponto de vista masculino que era moldado pela ideologia patriarcal vigente no século XIX.

A compreensão das personagens femininas na obra machadiana exige a princípio o conhecimento do personagem narrador e o ponto de vista através do qual o mesmo faz sua narrativa. Por isso, acreditamos que a releitura dos clássicos como fez o escritor Moacyr Scliar e outros escritores, é importante para compreendermos melhor os diferentes contextos que envolvem a literatura, além de percebemos a flexibilidade que esta possibilita ao leitor.

Mudando apenas o foco narrativo, Missa do Galo: Outro enfoque nos traz não apenas uma mudança na narrativa do conto, mas, sobretudo, na mudança de convicções e padrões estabelecidos em outra época, que nos dias atuais não persistem mais. Possibilita também aos leitores trazerem as análises de um conto escrito há mais de cem anos atrás para a sociedade do século XX, que tem outros princípios e na qual, apesar de alguns retrocessos, as mulheres ganham cada dia mais espaço no mercado do trabalho nos ambientes acadêmicos. Observamos, muitas vezes, um lado negativo nessa liberdade feminina, o fato de muitas estarem expostas aos padrões eurocêntricos de beleza e a busca intensa por visibilidade alimentada pela mídia brasileira. Muitas mulheres acabam tendo que, através da exposição desnecessária de seu corpo, ficar famosa e assim conseguir algum "status social".

Apesar da consciência de que ainda há muito a ser feito pela e para que as mulheres conquistem sua autonomia e emancipação, é inegável a contribuição dada pela literatura nesse processo, em particular por Machado de Assis, que além de ter revolucionado o modo de ver a sociedade e o comportamento das pessoas no seu tempo, permita que possamos compreender o nosso na contemporaneidade.

\section{Considerações Finais}

Consideramos que as reflexões feitas neste artigo foram importantes de alguma forma para o desenvolvimento dos estudos feitos acerca do conto secular do escritor Machado de Assis, bem como do escritor contemporâneo Moacyr Scliar. Além de levantarmos questões que problematizaram o papel da mulher em séculos passados e nos dias de hoeje, fazendo uma comparação dos costumes e hábitos femininos em uma sociedade patriarcal do século XIX e de uma sociedade na qual a mulher busca cada dia 


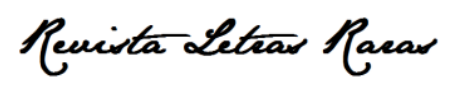

ISSN: 23172347 - Vol. 2 Nº. 2 - 2013

mais galgar espaços, antes privilegiados pelos homens e, na qual a mulher possui a liberdade de expor os seus sentimentos e de se comportar sem se preocupar com padrões e valores impostos de maneira machista.

\section{Referências}

ANDRADE, Jesuíno Aparecido. OLIVEIRA, Rita Nereide de. Personagens femininas na obra machadiana. Disponível em: www.portuguesdobrasil.net. Acesso realizado no dia 29 de Agosto de 2013.

ASSIS, Machado de. Missa do Galo e outros contos. Editora UNIFESP, 2011.

BARROS, Marta Cavalcante de. Espirais do desejo: As mulheres nos contos de Machado de Assis. Trabalho apresentado no Programa de Teoria Literária da Universidade de São Paulo, 2002.

SCLIAR. Moacyr. Missa do Galo: um outro enfoque. In: FERNANDES, Rinaldo de (org.). Capitu mandou flores: contos para Machado de Assis nos cem anos de sua morte. São Paulo: Geração Editorial, 2008, pp. 48-55.

WIKIPEDIA. Disponível em http://pt.wikipedia.org/wiki/Machado_de_Assis e em http://pt.wikipedia.org/wiki/Moacyr_Scliar. Acesso realizado no dia 27 de Agosto de 2013. 